\title{
Author Correction: Emission budgets and pathways consistent with limiting warming to $1.5^{\circ} \mathrm{C}$
}

Richard J. Millar, Jan S. Fuglestvedt, Pierre Friedlingstein, Joeri Rogelj, Michael J. Grubb, H. Damon Matthews, Ragnhild B. Skeie, Piers M. Forster, David J. Frame and Myles R. Allen

Correction to: Nature Geoscience https://doi.org/10.1038/ngeo3031, published online 18 September 2017.

In the version of this Article originally published, a coding error resulted in the erroneous inclusion of a subset of RCP4.5 and RCP8.5 simulations in the sets used for RCP2.6 and RCP6, respectively, leading to an incorrect depiction of the data of the latter two sets in Fig. $1 \mathrm{~b}$ and RCP2.6 in Table 2. This coding error has now been corrected. The graphic and quantitative changes in the corrected Fig. $1 \mathrm{~b}$ and Table 2 are contrasted with the originally published display items below. The core conclusions of the paper are not affected, but some numerical values and statements have also been updated as a result; these are listed below. All these errors have now been corrected in the online versions of this Article.

\section{Corrected statements.}

Statement 1 (section: Abstract)

\section{Original:}

“... Earth system model members of the CMIP5 ensemble with no mitigation of other climate drivers, increasing to $240 \mathrm{GtC}$ with ambitious non- $\mathrm{CO}_{2}$ mitigation."

\section{Corrected:}

“... Earth system model members of the CMIP5 ensemble with no mitigation of other climate drivers."

Statement 2 (section: Carbon budgets and scenarios for ambitious climate goals)

\section{Original:}

"This allows more $\mathrm{CO}_{2}$-induced warming for the same total, increasing the median TEB of the CMIP5 distribution for an additional 0.6 ${ }^{\circ} \mathrm{C}$ to $303 \mathrm{GtC}$ and the 66 th percentile to $242 \mathrm{GtC}$.

\section{Corrected:}

"This should allow more $\mathrm{CO}_{2}$-induced warming for the same total. However, due to the smaller subset of available models in the RCP2.6 scenario, it is not possible to identify any robust shifts in the percentiles of the TEB distribution from the RCP8.5 scenario."

\section{Statement 3 (section: Adaptive mitigation and carbon budgets)}

\section{Original:}

“...in good agreement with the $242 \mathrm{GtC}$ TEB for the 66th percentile of the CMIP5 distribution for $0.6{ }^{\circ} \mathrm{C}$ warming above the $2010-2019$ average in the RCP2.6 scenario (Table 2)."

\section{Corrected:}

“...about $25 \%$ higher than the 204 GtC TEB for the 66th percentile of the CMIP5 distribution for $0.6{ }^{\circ} \mathrm{C}$ warming above the $2010-2019$ average in the RCP8.5 scenario (Table 1)." 


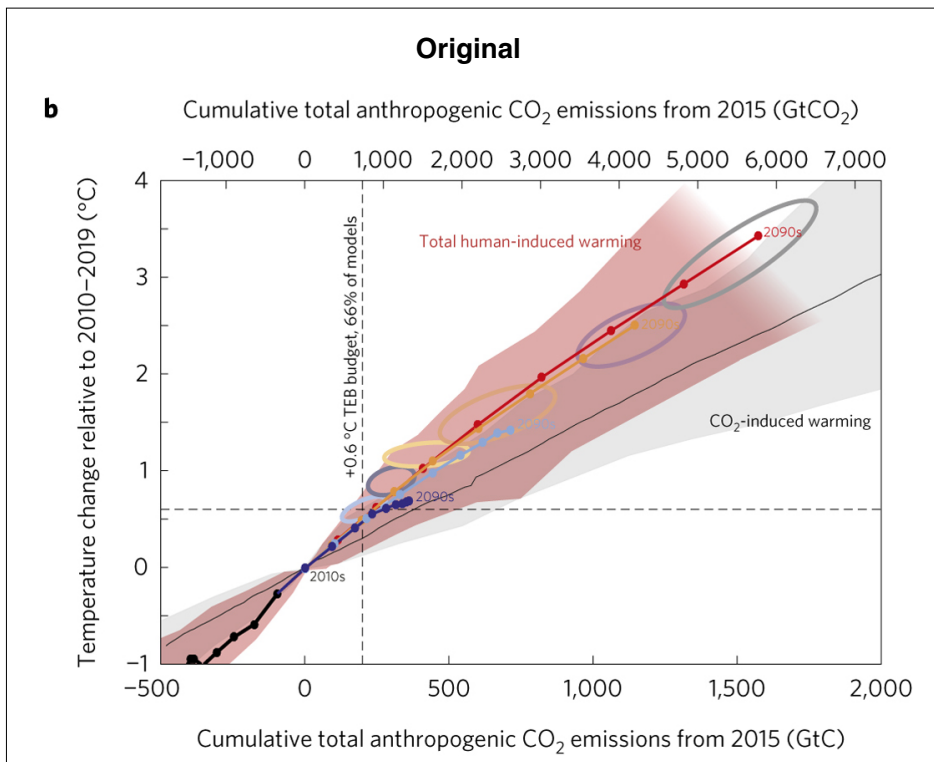

\section{Corrected}

b Cumulative total anthropogenic $\mathrm{CO}_{2}$ emissions from $2015\left(\mathrm{GtCO}_{2}\right)$

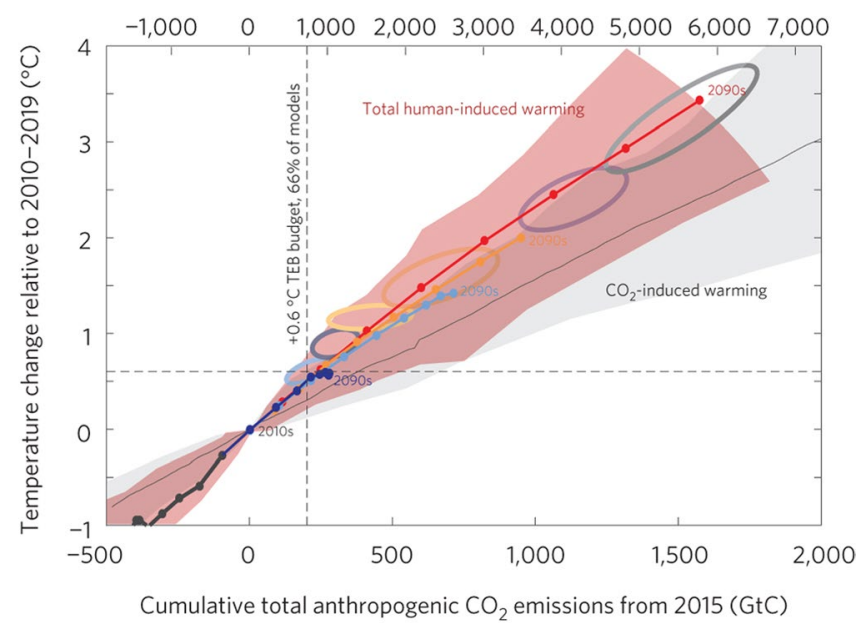

Fig. 1b | Original and corrected panels.

Table 2 | The original and corrected values of Table 2 in the originally published Article. Future cumulative budgets (GtC) from January 2015 for percentiles of the distribution of RCP2.6 simulations of CMIP5 models and various levels of future warming above the modelled 2010-2019 average.

\begin{tabular}{|c|c|c|c|c|c|}
\hline Warming above & & Perce & es of C & $5 \mathrm{mod}$ & \\
\hline $\begin{array}{l}2010-2019 \text { average } \\
\left({ }^{\circ} \mathrm{C}\right)\end{array}$ & $90 \%$ & $66 \%$ & $50 \%$ & $33 \%$ & $10 \%$ \\
\hline
\end{tabular}

\begin{tabular}{llllll}
\hline (a) Original & & & & & \\
$\mathbf{0 . 3}$ & 89 & 106 & 118 & 133 & 245 \\
$\mathbf{0 . 4}$ & 106 & 152 & 173 & 193 & NA \\
$\mathbf{0 . 5}$ & 126 & 191 & 214 & 258 & NA \\
$\mathbf{0 . 6}$ & 143 & 242 & 303 & NA & NA \\
$\mathbf{0 . 7}$ & 170 & 291 & NA & NA & NA \\
$\mathbf{0 . 8}$ & 177 & 372 & NA & NA & NA \\
$\mathbf{0 . 9}$ & 277 & NA & NA & NA & NA \\
$\mathbf{1 . 0}$ & 468 & NA & NA & NA & NA \\
$\mathbf{1 . 1}$ & NA & NA & NA & NA & NA
\end{tabular}

$\begin{array}{llllll}\text { (b) Corrected } & & & & & \\ \mathbf{0 . 3} & 88 & 104 & 123 & 127 & 273 \\ \mathbf{0 . 4} & 106 & 152 & 162 & 206 & \text { NA } \\ \mathbf{0 . 5} & 126 & 171 & 194 & 247 & \text { NA } \\ \mathbf{0 . 6} & 143 & 196 & 352 & \text { NA } & \text { NA } \\ \mathbf{0 . 7} & 160 & 224 & \text { NA } & \text { NA } & \text { NA } \\ \mathbf{0 . 8} & 178 & 280 & \text { NA } & \text { NA } & \text { NA } \\ \mathbf{0 . 9} & \text { NA } & \text { NA } & \text { NA } & \text { NA } & \text { NA } \\ \mathbf{1 . 0} & \text { NA } & \text { NA } & \text { NA } & \text { NA } & \text { NA } \\ \mathbf{1 . 1} & \text { NA } & \text { NA } & \text { NA } & \text { NA } & \text { NA }\end{array}$

Published online: 14 May 2018

https://doi.org/10.1038/s41561-018-0153-1 